OPEN ACCESS

Edited by:

Lloyd Reeve-Johnson, University of the Sunshine

Coast, Australia

Reviewed by:

Benito Soto-Blanco, Federal University of Minas

Gerais, Brazil

Cengiz Gokbulut,

Ballkesir University, Turkey

*Correspondence:

Ronald H. L. L

rhli@ucdavis.edu

Specialty section: This article was submitted to Veterinary Pharmacology and Toxicology,

a section of the journal Frontiers in Veterinary Science

Received: 15 February 2020 Accepted: 21 April 2020 Published: 27 May 2020

Citation:

Li RHL, Nguyen N, Rosati T and Jandrey K (2020) Assessment of P2Y $Y_{12}$ Inhibition by Clopidogrel in Feline Platelets Using Flow Cytometry

Quantification of

Vasodilator-Stimulated

Phosphoprotein Phosphorylation.

Front. Vet. Sci. 7:267.

doi: 10.3389/fvets.2020.00267

\section{Assessment of P2Y 12 Inhibition by Clopidogrel in Feline Platelets Using Flow Cytometry Quantification of Vasodilator-Stimulated Phosphoprotein Phosphorylation}

\author{
Ronald H. L. Li ${ }^{1 *}$, Nghi Nguyen ${ }^{1}$, Tommaso Rosati ${ }^{2}$ and Karl Jandrey ${ }^{1}$ \\ ${ }^{1}$ Department of Veterinary Surgical and Radiological Sciences, School of Veterinary Medicine, University of California, Davis, \\ Davis, CA, United States, ${ }^{2}$ William R. Pritchard Veterinary Medical Teaching Hospital, University of California, Davis, Davis, \\ CA, United States
}

The primary objective of this study was to evaluate a novel flow cytometry-based assay of quantifying platelet phosphorylation of vasodilator-stimulated phosphoprotein (P-VASP) in cats that received clopidogrel treatment. Eight healthy cats received $18.75 \mathrm{mg} \mathrm{PO} \mathrm{q24h}$ of clopidogrel for 7 days. Prior to and after clopidogrel treatment, blood was collected for ADP-induced light transmission aggregometry (LTA) and P-VASP measurement by flow cytometry. Flow cytometry measurement of P-VASP levels was used to derive platelet reactivity index (PRI) before and after clopidogrel treatment. Based on P-VASP and LTA findings, platelet response to ADP was significantly attenuated after 7 days of clopidogrel treatment. By eliciting the competing platelet pathways of $\mathrm{P}_{2} \mathrm{Y}_{12}$ and cAMP using ADP and $P \mathrm{PE}_{1}$, respectively, ADP had no effect on P-VASP levels following clopidogrel treatment $(p=0.94)$. Clopidogrel also significantly decreased PRI from 28.84 $\pm 28.52 \%$ to $1.69 \pm 12.39 \%(p=0.0078)$. PRI on day 8 correlated moderately with the degree of slope inhibition on LTA $(r=-0.4, p=0.4)$. Flow cytometry analysis of P-VASP is effective at monitoring the inhibitory effects of clopidogrel on feline platelets.

\footnotetext{
Keywords: hypertrophic cardiomyopathy, platelet activation and signaling, light transmission aggregometry, vasodilator stimulated phosphoprotein, cyclic AMP
}

\section{INTRODUCTION}

Hypertrophic cardiomyopathy (HCM) is the most common cardiomyopathy in cats affecting $\sim 15 \%$ of the feline population (1). Since cardiogenic arterial thromboembolism (CATE) is one of the most devastating sequelae of HCM in cats, anti-platelet drugs like aspirin and clopidogrel are the cornerstone of anticoagulant therapy in these cats (2-5). Clopidogrel, once metabolized to its active metabolite by hepatic cytochrome P450, inhibits ADP-mediated platelet activation by covalently binding onto one of the two G protein-coupled ADP receptors, $\mathrm{P}_{2} \mathrm{Y}_{12}$. This irreversibly prevents $A D P$ from activating the $G$ protein, $G_{i 2 a}$, responsible for downstream signaling that amplifies platelet activation and aggregation (6). A randomized controlled trial in cats with CATE demonstrated the superiority of clopidogrel over aspirin in reducing recurrent thrombotic events (7). Despite this favorable outcome, recurrence of CATE remains high, thus, underscoring the highly variable pharmacodynamic response to clopidogrel in clinical HCM cats. Because 
clopidogrel resistance has long been associated with ontreatment thrombotic events in human patients, a reliable and accurate assay to measure clopidogrel response in cats is needed.

In response to $\mathrm{P}_{2} \mathrm{Y}_{12}$ inhibition or prostaglandin $\mathrm{E}_{1}\left(\mathrm{PGE}_{1}\right)$, platelet cyclic adenosine monophosphate (cAMP) is elevated resulting in protein kinase $\mathrm{A}$ activation and subsequent phosphorylation of the actin regulatory protein, vasodilatorstimulated phosphoprotein (VASP) (8). Conversely, platelet activation by the agonist, ADP, inhibits cAMP production and dephosphorylation of VASP. The degree of VASP phosphorylation (P-VASP) within platelets, therefore, serves as a marker of $\mathrm{P}_{2} \mathrm{Y}_{12}$ activation or inhibition $(9,10)$. The authors had previously evaluated P-VASP in feline platelets using Western blot analysis. Although a significant increase in P-VASP was found in response to clopidogrel therapy, interindividual variability was extremely high (11). In addition, protein analysis by Western blot only yielded semi-quantitative results that were subjected to high inter-operator variability. For that reason, intraplatelet P-VASP analysis by quantitative flow cytometry has been extensively studied in human beings. In human studies, P-VASP quantification by flow cytometry has been shown to be sensitive in monitoring the inhibitory effects of $\mathrm{P}_{2} \mathrm{Y}_{12}$ antagonists $(9,12)$. However, quantification of platelet P-VASP by flow cytometry as a marker of inhibitory and stimulatory pathways has never been evaluated in cats.

Herein, we described a new flow cytometry-based method to measure the inhibitory effects of clopidogrel in cats by quantifying P-VASP within feline platelets. We also aimed to evaluate the pharmacodynamic response to clopidogrel by correlating flow cytometric measurement of platelet P-VASP to ADP-induced LTA in cats treated with 7 days of clopidogrel. We hypothesized that clopidogrel treatment in cats would lead to intracellular inhibitory pathways resulting in phosphorylation of VASP and that the degree of platelet VASP phosphorylation would correlate with inhibition in ADP-induced aggregation as measured by LTA.

\section{MATERIALS AND METHODS}

\section{Animals and Study Design}

The study protocol was approved by the Institutional Animal Care and Use Committee at the University of California, Davis (IACUC \#20359). Eight university-owned, domestic shorthaired cats from the Feline Nutrition and Pet Care Center at University of California, Davis were used in this study. The mean age of cats was 4.5 years (range: 2-5 years). All cats were female spayed Domestic Shorthair cats. All cats were not enrolled in other studies at the time of data collection and were deemed to be clinically healthy based on physical examinations performed by the authors prior to the study. Prior to clopidogrel therapy (day 0 ), $4 \mathrm{ml}$ of whole blood was collected from the jugular vein or medial saphenous vein using a 20 -gauge needle or 21-gauge butterfly catheter, and, immediately aliquoted to $3.2 \%$ trisodium citrate tubes. Each cat then received $18.75 \mathrm{mg}$ clopidogrel bisulfate (1/4 of a $75 \mathrm{mg}$ Plavix ${ }^{\circledR}$ tablet, Britol-Myers Squibb/Sanofi Pharmaceuticals, Bridgewater, NJ) every $24 \mathrm{~h}$ PO for 7 days. The tablet was administered to each cat using a pilling device to insert the tablet into the oral cavity over the base of the tongue. Cats were then observed to swallow to confirm that the dose was administered. All cats were monitored closely for adverse effects such as vomiting, lethargy, inappetence, diarrhea and bleeding diathesis throughout the study period. Blood was drawn, as described above, $\sim 12 \mathrm{~h}$ after the last dose of clopidogrel (Day 8).

\section{Generation of Platelet Rich Plasma}

Following thorough mixing of anticoagulant, blood was transferred to round-bottom polypropylene tubes and placed in $37^{\circ} \mathrm{C}$ bead bath for $30 \mathrm{~min}$ to facilitate sedimentation of erythrocytes. Platelet rich plasma (PRP) was then generated by centrifugation at $200 \mathrm{x} \mathrm{g}$ for $5 \mathrm{~min}$ (no brakes, $25-27^{\circ} \mathrm{C}$ ). Complete blood count of whole blood and platelet count of PRP were obtained using an automated analyzer (HM5, Abaxis, Union City, CA) and confirmed by blood smear evaluation. All samples were analyzed within $2 \mathrm{~h}$ after collection.

\section{Cell Preparation and Immunolabelling}

Platelet concentration in PRP was standardized to $2 \times 10^{7} / \mathrm{ml}$ with Tyrodes HEPES ( $\mathrm{pH} 7.2,5 \mathrm{mM}$ dextrose without divalent cations) to a final volume of $100 \mu \mathrm{l}$ (11). Platelets were treated with $10 \mu \mathrm{M} \mathrm{PGE}_{1}$ (MilliporeSigma, Burlington, MA), as positive control, $20 \mu \mathrm{M}$ ADP (MilliporeSigma, Burlington, MA), or with a combination of $\mathrm{ADP}$ and $\mathrm{PGE}_{1}$ for $15 \mathrm{~min}$ at $37^{\circ} \mathrm{C}$. Platelets were then fixed in $1 \%$ methanol-free paraformaldehyde for $15 \mathrm{~min}$ at room temperature. Immediately after permeabilization using $0.25 \%$ detergent (NP-40 Surface-AMPs Detergent Solution, ThermoFisher), PRP was subjected to centrifugation at 5,000 $\times$ $\mathrm{g}$ for $1 \mathrm{~min}$ at room temperature. Supernatant was immediately discarded, and pellets were resuspended with $100 \mu$ l Tyrodes HEPES (no divalent cations). Phosphorylation at serine-239 of VASP was detected using a mouse polyclonal antibody conjugated to fluorescein isothiocyanate $(5 \mathrm{ug} / \mathrm{mL}$, ALX-804240F-C100, Enzo Life Sciences, Farmingdale, NY) for $90 \mathrm{~min}$ at room temperature (protect from light). The amino acid sequence of P-VASP is highly homologous when compared to the published feline VASP protein sequence as determined by the Basic Local Alignment Search Tool, BLAST (National Institute of Health).

\section{Flow Cytometry}

Platelets were analyzed within $2 \mathrm{~h}$ following fixation, permeabilization and labeling. PRP were further diluted (1:10) with Tyrodes HEPES before filtering through a cell strainer prior to analysis. Flow cytometry was performed using a 5-color flow cytometer (Beckman-Coulter FC500 Flow Cytometer, Beckman-Coulter Inc). Platelets were identified by forward- and side-scatter properties as previously described (11) using 0.9 and $3 \mu \mathrm{m}$ calibration beads and each sample was analyzed until 10,000 events were recorded (Figure 1A). In brief, gating of P-VASP-positive events was established by isotype and fluorescence-minus-one controls consisting of unlabeled cells that were subjected to the same experimental conditions (Figures 1B,C). Mean fluorescence intensity (MFI) of 


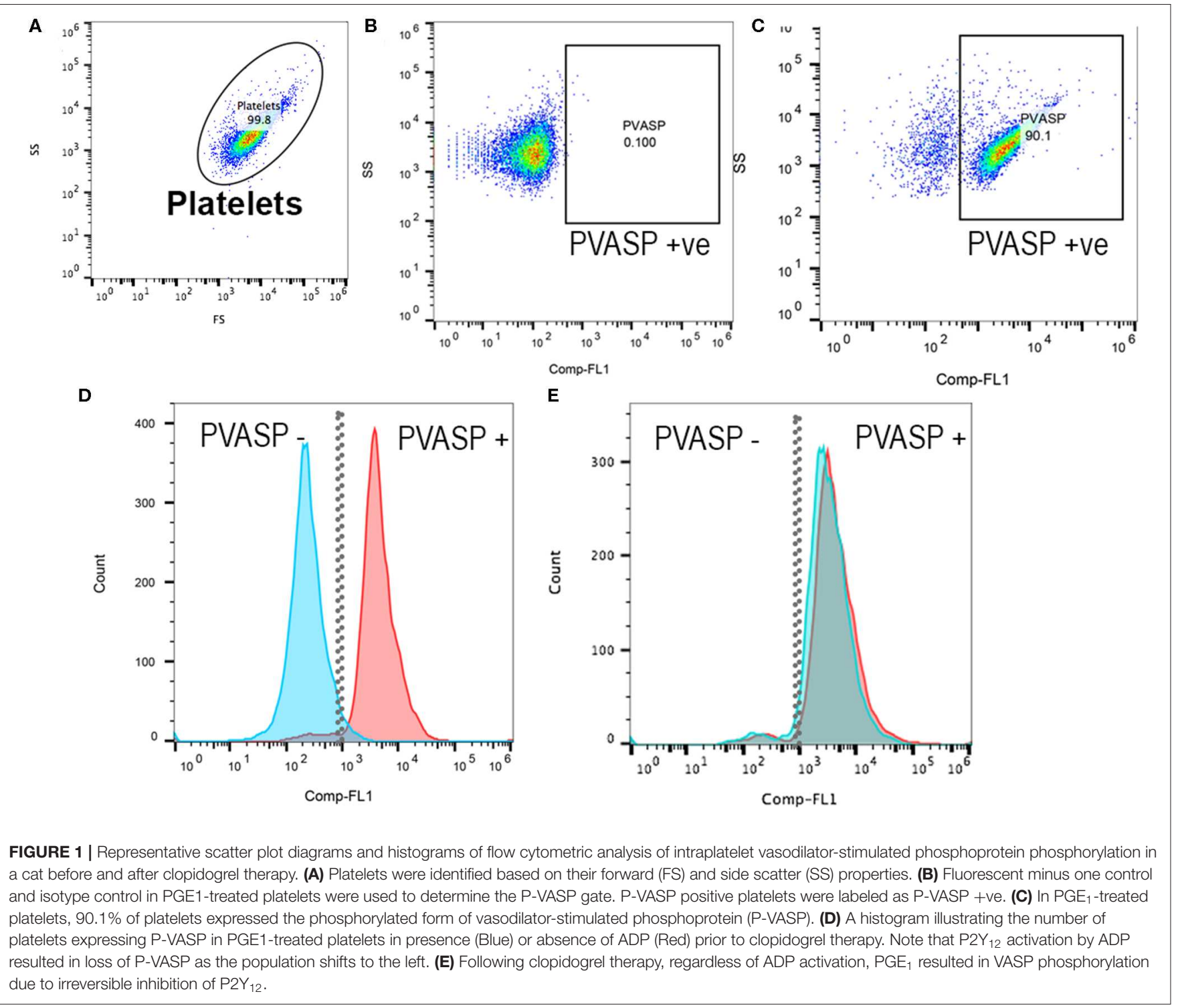

P-VASP positive platelets (Figures 1D,E) were measured using commercially available software (Flowjo, Ashland, Oregon).

\section{Light Transmission Aggregometry}

PRP generated from citrated whole blood was diluted to 1.5 $\times 10^{8} / \mathrm{ml}$ using Tyrodes-HEPES ( $\mathrm{pH} 7.2,5 \mathrm{mM}$ dextrose, no divalent cations). Platelet poor plasma, generated by centrifugation at $10,000 \times \mathrm{g}$ for $5 \mathrm{~min}$, from each cat served as the control light transmission. PRP was aliquoted to warmed siliconized cuvettes (Chronolog, Havertown, PA) containing a magnetic stir bar set at a constant stir speed of 1,200 rpm. Aggregation was then recorded for $1 \mathrm{~min}$ as baseline before the addition of $40 \mu \mathrm{M}$ ADP or $1 \mathrm{U} / \mathrm{ml}$ bovine $\alpha$-thrombin (Haematologic Technologies, Essex Junction, VT), utilized as positive control. Aggregation was recorded for an additional $5 \mathrm{~min}$ and measured as percent (\%) of maximum aggregation, slope and area under the curve (AUC) transmission using commercially available software (Chronolog, Havertown, PA), as previously validated for use in cats (11).

\section{Response to Clopidogrel}

The inhibitory effect of clopidogrel on platelets was categorized based on previously established criteria (11). Percent (\%) inhibition by clopidogrel based on ADP-induced aggregation (ADP-Ag), was measured by \% aggregation, slope and AUC, was calculated using Equation (1).

$$
\begin{aligned}
& \text { Percent inhibition }(\%)= \\
& \frac{(\mathrm{ADP}-\mathrm{Ag} \text { Day0 }-\mathrm{ADP}-\mathrm{Ag} \text { Day8 })}{\mathrm{ADP}-\mathrm{Ag} \text { Day0 }} \times 100
\end{aligned}
$$

For the purpose of this study, cats with $<60 \%$ inhibition were classified as non-responders (11). The magnitude of $\mathrm{P}_{2} \mathrm{Y}_{12}$ 
inhibition was measured by the platelet reactivity index (PRI), calculated based on P-VASP MFI using Equation (2) (13):

$$
\mathrm{PRI}=\left[\frac{\left(\mathrm{MFI}_{\mathrm{PGE1}}-\mathrm{MFI}_{\mathrm{PGE} 1+\mathrm{ADP}}\right)}{\mathrm{MFI}_{\mathrm{PGE} 1}}\right] \times 100
$$

\section{Statistical Analysis}

Normality of data was tested using Shapiro-Wilk normality test or visual inspection of normal quartile plots. Nonparametric data were presented as median and interquartile range (IQR) and parametric data were presented as mean \pm standard deviation. Normally distributed and paired data were analyzed using paired $t$-tests while nonparametric and paired data were analyzed using Wilcoxon signed-rank test. To evaluate correlation between P-VASP PRI and LTA findings, Spearman correlation and correlation coefficient were calculated using standardized units [Standardized $\times=(\times$-mean $) /$ standard deviation]. An alpha-priori of $<0.05$ was considered statistically significant. Interindividual variability was calculated as the ratio between the standard deviation of a group and its means and expressed as coefficient of variation $(\mathrm{CV})$. Data were analyzed using commercially available software (Prism 8.0, GraphPad Software, La Jolla, CA).

\section{RESULTS}

No adverse effects secondary to clopidogrel were observed throughout the study period. Mean platelet count on day 0 was $310 \times 10^{9} / \mathrm{ml} \pm 62$, which was significantly lower than platelet count on day $8\left(415 \times 10^{9} / \mathrm{ml} \pm 103, p=0.0032\right)$ following clopidogrel therapy.

\section{Flow Cytometric P-VASP Analysis}

On day 0 , compared to $\mathrm{PGE}_{1}$-treated platelets, ADP-activated platelets expressed significantly lower levels of P-VASP $(4,332 \pm$ $1,115$ vs. $1,245 \pm 628.9, p<0.0001)$. $\mathrm{PGE}_{1}$ in the presence of ADP also resulted in significantly lower P-VASP levels $(3,038 \pm$ 1,420 vs. $4,332 \pm 1,115, p=0.026$ ) (Figure $2 A$ ). After 7 days of clopidogrel treatment, P-VASP in $\mathrm{PGE}_{1}$-treated platelets was not significantly different from P-VASP in platelets treated with $\mathrm{ADP}$ and PGE1-treated platelets $(\mathrm{MFI}=3,787 \pm 633.5$ vs. 3,803 $\pm 686.6, p=0.94)$. ADP-treated platelets continued to have significantly lower P-VASP compared to $\mathrm{PGE}_{1}$-treated platelets $(1,072 \pm 458.8$ vs. $3,787 \pm 633.5, p<0.0001)$ (Figure 2B).

\section{Light Transmission Aggregometry}

On day 0, the mean ADP-Ag was $57.29 \pm 24.03 \%$ and was significantly decreased following 7 days of clopidogrel treatment $(8.75 \pm 7.44 \%, p=0.0038)$ (Figure 3A). Thrombin, as positive control, did not induce significant differences in aggregation between days 0 and 8 (90.13 $\pm 8.66 \%$ vs. $102.4 \pm 14.34 \%, p$ $=0.05$ ). Similarly, slopes and AUC were significantly different decreased after 7 days of clopidogrel treatment (AUC: $255.90 \pm$ 108.6 vs. $37.91 \pm 35.74, p=0.0017$, Slope: $99.29 \pm 31.80$ vs. 28.38 $\pm 27.53, p=0.0090$ ) (Figures 3B,C).

\section{Variability in Clopidogrel Response}

The mean PRI based on P-VASP levels on day 0 was $28.84 \pm$ $28.52 \%$. The mean PRI after 7 days of clopidogrel therapy was significantly lower at $1.69 \pm 12.39 \%(p=0.0078)$ (Figure 4A). Standard deviations of PRI measured by P-VASP on days 0 and 8 were 28.52 and $12.39 \%$, respectively. Coefficient of variations were $98.91 \%$ (range: $6.22-87.04 \%$ ) and $732.93 \%$ (range: -13.33 to $20.57 \%$ ) on days 0 and 8 , respectively.
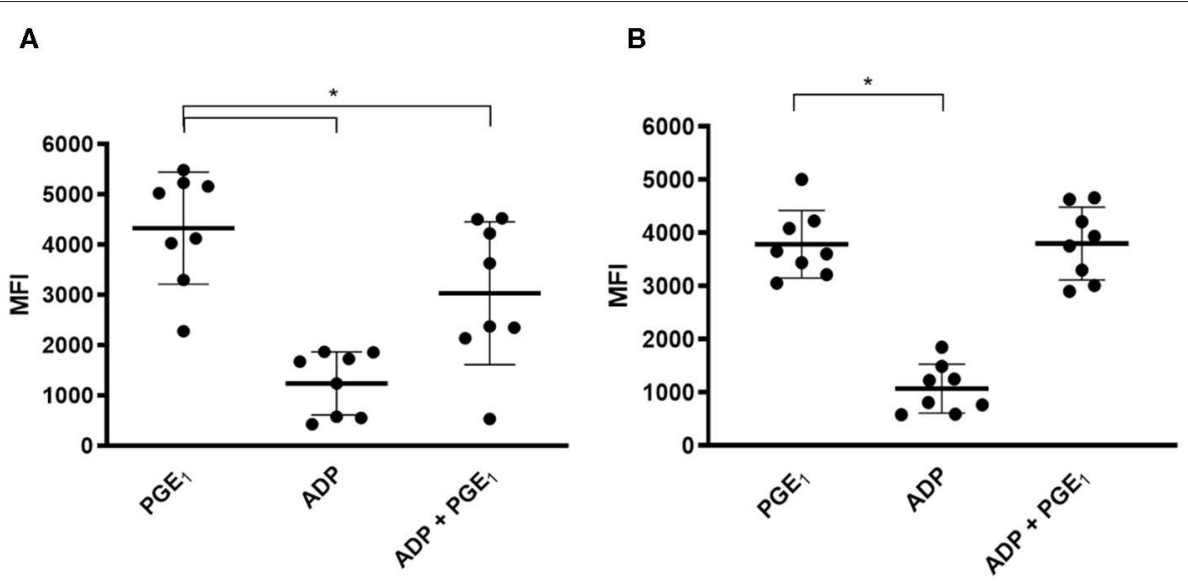

FIGURE 2 | Scatter dot plots of intraplatelet vasodilator-stimulated phosphoprotein phosphorylation (P-VASP) in eight cats before and after 7 days of clopidogrel therapy. Platelet rich plasma from eight cats treated with PGE1, ADP or a combination of PGE1 and ADP was evaluated for P-VASP expression, as quantified by mean fluorescence intensity (MFI) using flow cytometry. (A) Before clopidogrel therapy, ADP-induced platelet activation in the presence of PGE ${ }_{1}$ resulted in significant decrease in P-VASP expression compared to PGE-1 treated platelets in the absence of ADP. (B) Following clopidogrel therapy, ADP in the presence of PGE 1 did not result in significant decrease in $\mathrm{P}$-VASP expression compared to $\mathrm{PGE}_{1}$-treated platelets. ADP-induced platelet activation resulted in significant decrease in $\mathrm{P}$-VASP expression regardless of clopidogrel treatment. Middle line represents the median and upper and lower lines represent the 25 th and 75 th quartile, respectively. ${ }^{*} p<0.05$. 
Based on LTA, $3 / 8$ cats (37.5\%) were identified as nonresponders with percent inhibition of $48.1,55.0$, and $6 \%$ (Figure 3). The median percent inhibition among responders was 93.42\% (IQR: 77.76-97.79). Prior to clopidogrel therapy, the median PRI among the three non-responders was $56.66 \%$ (IQR: 9.97-87.04). Responders, on the other hand, had a median baseline PRI of 13.84\% (IQR: 9.29-22.30) (Figure 4B). Median PRI was $-13.33 \%$ (IQR: -22.95 to 6.252 ) and $3.983 \%$ (IQR: -9.744 to 18.21 ) among the three non-responders and responders, respectively, following clopidogrel therapy (Figure 4C).

\section{Correlation Between ADP-Induced Light-Transmission Aggregometry and Platelet Reactivity Index Based on Flow Cytometric P-VASP}

The correlations between ADP-induced LTA and PRIs on days 0 and 8 are summarized in Table 1. PRI based on P-VASP correlated moderately, but not significantly, with percent inhibition of slope based on ADP-induced LTA on day 8.

\section{DISCUSSION}

This is the first study to report the use of flow cytometry quantification of platelet P-VASP in healthy cats following clopidogrel treatment. We demonstrated that $\mathrm{P}_{2} \mathrm{Y}_{12}$ activation by ADP significantly diminishes platelet P-VASP levels in the presence of $\mathrm{PGE}_{1}$. On the other hand, irreversible inhibition of $\mathrm{P}_{2} \mathrm{Y}_{12}$ by clopidogrel results in sustained phosphorylation of VASP when platelets are in the presence of $\mathrm{PGE}_{1}$ and ADP. We also found that PRI based on platelet P-VASP following 7 days of clopidogrel treatment in cats had a moderate but insignificant correlation with ADP-induced LTA.

ADP-mediated platelet activation via $\mathrm{P}_{2} \mathrm{Y}_{12}$ and platelet inhibition by endothelial factors like prostacyclin, prostaglandin or nitric oxide are competing pathways regulated by cAMP $(8,10) . \mathrm{P} \mathrm{Y}_{12}$ antagonists like clopidogrel active metabolite offsets this balance by modulating the activation of adenyl cyclase and subsequently increasing cAMP production, which inhibits platelet function $(14,15)$. We elicited these competing cAMPregulated pathways by treating platelets with $\mathrm{ADP}$ and $\mathrm{PGE}_{1}$ simultaneously. Measurement of phosphorylation of VASP, a substrate of cAMP-dependent kinases like protein kinase A, therefore, can be a marker of platelet inhibition and, specifically, $\mathrm{P}_{2} \mathrm{Y}_{12}$ antagonism. In agreement with our previous study, which utilized protein electrophoresis and Western blot analysis in platelet lysate, we were able to detect irreversible $\mathrm{P}_{2} \mathrm{Y}_{12}$ inhibition in clopidogrel-treated cats by measuring intraplatelet P-VASP levels within platelets using flow cytometry (11).

Flow cytometry has been used in cats to evaluate surface protein expression, platelet-leukocyte interaction, integrin activation and the shedding of platelet-derived microvesicles $(11,16)$. However, it has never been used to evaluate protein phosphorylation within feline platelets. In contrast to gelelectrophoresis and Western blot analysis, flow cytometry does not require multiple blocking and immunolabeling steps,

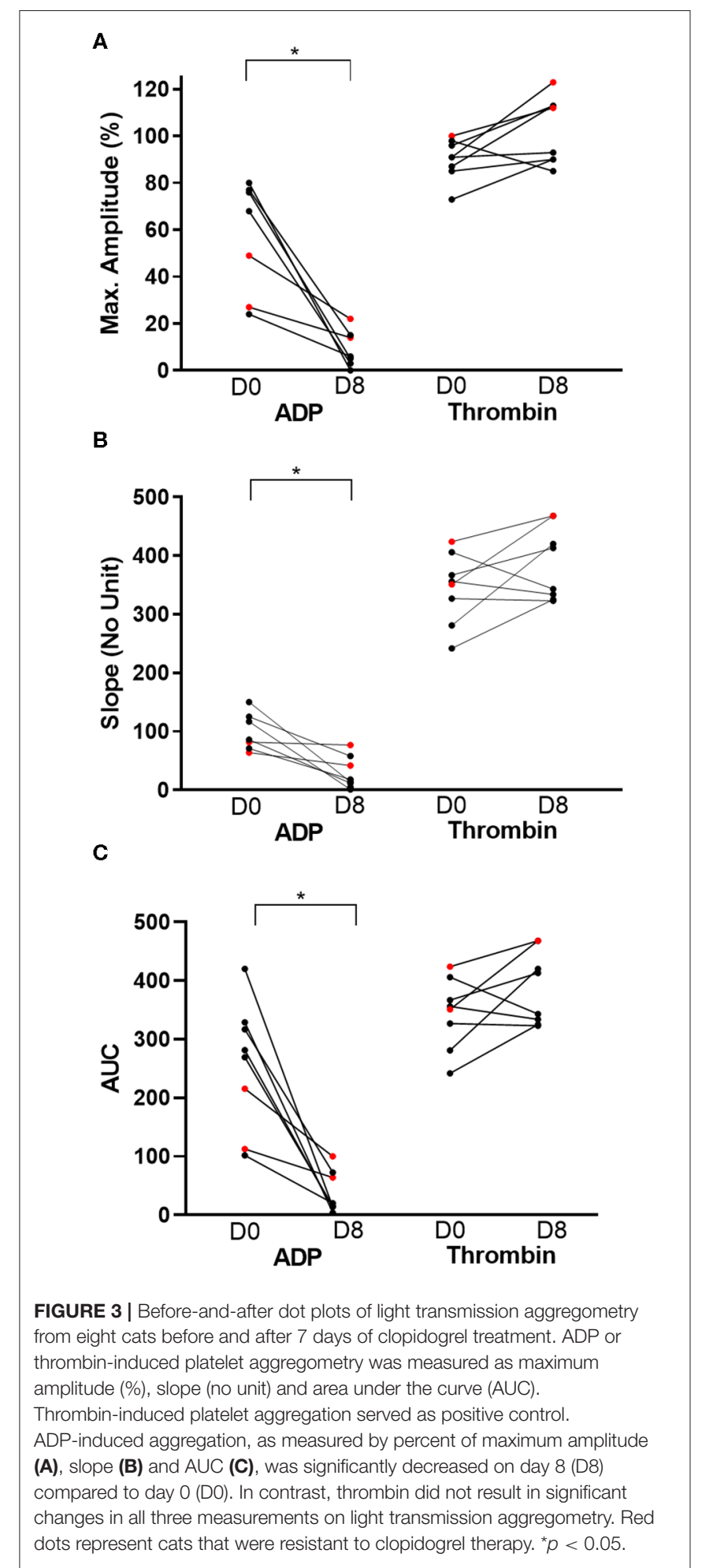

both of which can be labor intensive and time consuming. Still, intracellular protein detection by flow cytometry requires fixation and cell membrane permeabilization prior to the immunolabelling step. Fixation of platelets by paraformaldehyde or formaldehyde leads to crosslinking of methylene bridges 


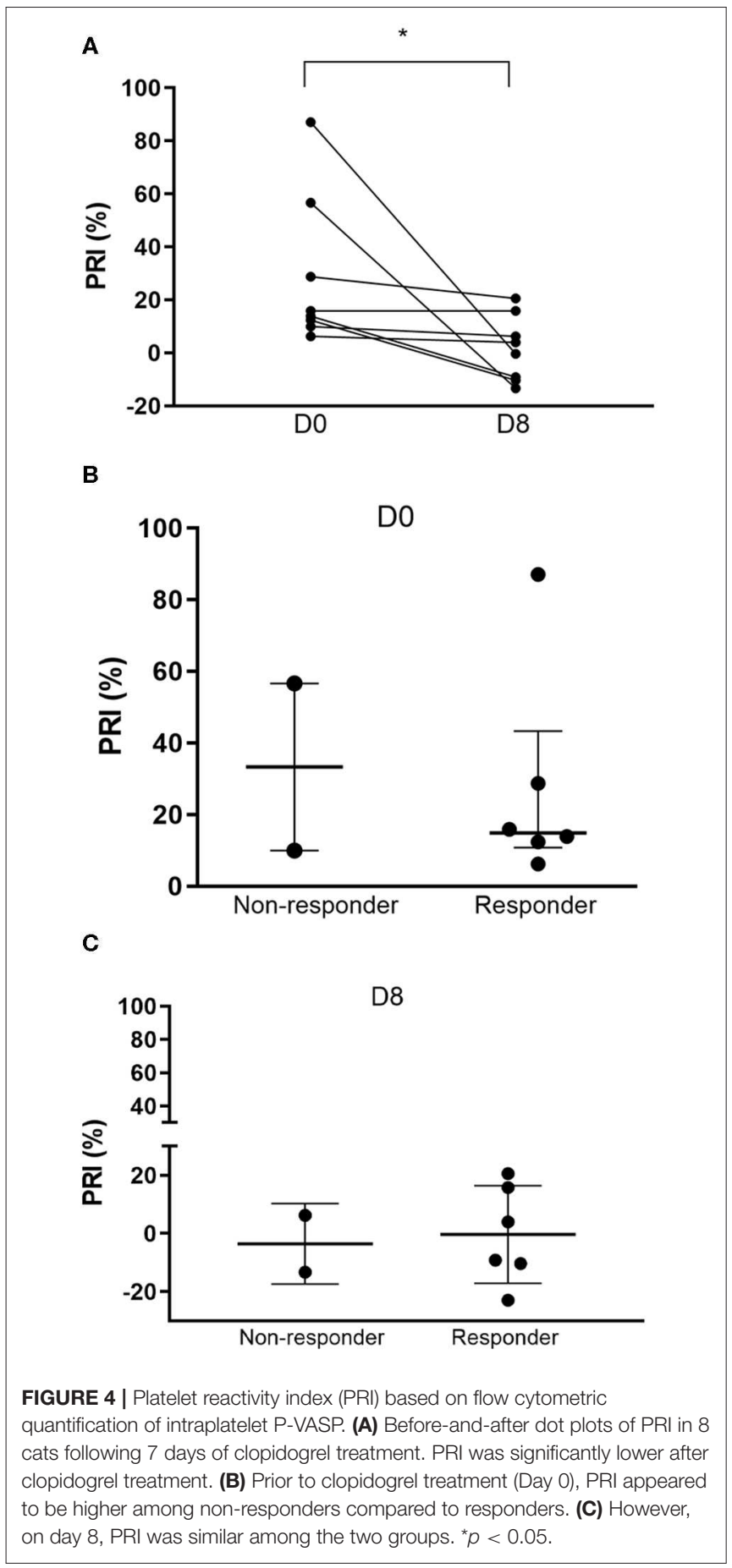

which stabilizes and immobilizes intracellular proteins. We recommend using methanol-free paraformaldehyde as the oxidation of formaldehyde can generate formic acid and ketones that may lead to artifact and autofluorescence during analysis (17). Prolonged fixation or fixation using high concentrations of paraformaldehyde can also mask the antigen of interest preventing the binding of fluorochrome-conjugated antibodies (18). For antibodies to detect intracellular proteins, the cell
TABLE 1 | Correlation between platelet reactivity index based on flow cytometric P-VASP and ADP-induced light transmission aggregometry.

\begin{tabular}{|c|c|c|c|c|}
\hline & \multicolumn{4}{|c|}{ PRI (P-VASP) } \\
\hline & Day 0 & & Day 8 & \\
\hline & $r$-value & $p$-value & $r$-value & $p$-value \\
\hline \multicolumn{5}{|c|}{ LTA (\% inhibition) } \\
\hline Amplitude & -0.46 & 0.30 & -0.089 & 0.90 \\
\hline Slope & -0.11 & 0.83 & -0.40 & 0.40 \\
\hline AUC & -0.19 & 0.66 & -0.089 & 0.90 \\
\hline
\end{tabular}

membrane must first be permeabilized with a detergent. We found that brief permeabilization in low concentration of detergent $(<0.5 \%)$, followed by a quick washing step, prevents significant alteration of the light scatter profiles of platelets and autofluorescence as a result of micelle formation and loss of the cytoplasm (Figure 1). Alternatively, permeabilization can be achieved using ice cold methanol.

LTA is considered the "gold standard" for monitoring anti-platelet therapy, although this has not been consensually recommended in veterinary medicine (19). To determine if flow cytometry quantification of P-VASP corresponds with LTA in cats, we calculated the correlation between PRI based on P-VASP and changes in LTA parameters before and after clopidogrel treatment. Despite the small number of cats in this study, we found moderate but insignificant correlation between P-VASP PRI and slope inhibition based on LTA. The slope of LTA tracings is calculated based on the rate of platelet aggregation in response to a platelet agonist. In the presence of low concentrations of ADP or $\mathrm{P}_{2} \mathrm{Y}_{12}$ inhibition, the rate of aggregation or slope fluctuates as platelets oscillate between aggregation and de-aggregation states due to the insufficient amount of ADP to trigger full aggregation (20). Without concurrent activation of $\mathrm{P}_{2} \mathrm{Y}_{12}$, activation of $\mathrm{P} 2 \mathrm{Y}_{1}$ by ADP results in elevation in cytosolic calcium but insufficient shape change and activation of the integrin, $\alpha_{\mathrm{IIb}} \beta_{3}$, to sustain aggregation (21). This may result in decreases in slope of LTA and PRI following clopidogrel treatment.

Like previous studies in cats, we found a high interindividual variability in response to a standard dose of clopidogrel. The proportion of clopidogrel non-responders in this study is also similar to a different population of cats with the genetic predisposition to $\operatorname{HCM}(11,22,23)$. Based on a study by Lee et al. (23), this pharmacodynamic variability could be explained by nonsynonymous single nucleotide polymorphisms in the feline CYP2C genes, responsible for encoding the cytochrome $\mathrm{P}$ isoenzymes for metabolizing clopidogrel to its active metabolite. However, no studies to date have documented the phenotypes of these mutations in cats based on clopidogrel-specific platelet function assays. We found that low responders may have an exaggerated response to ADP as demonstrated by elevated PRI prior to clopidogrel therapy, suggesting that mutations of other genes like P2RY12 and P2RY1, which encode the platelet ADP purinergic receptors, may play a role in clopidogrel resistance in cats. Because changes in P-VASP are specific at monitoring 
the inhibitory effects of clopidogrel, further studies using flow cytometry analysis of P-VASP are needed to assess the impact of genetic polymorphisms on the pharmacodynamics of clopidogrel in cats.

Given the small number of cats in this study, we were unable to identify a cut-off of PRI to differentiate between responders and non-responders after clopidogrel treatment. On the other hand, we found a trend suggesting that responders and non-responders had similar PRI following clopidogrel treatment. There are several explanations to this observation. First, for the purpose of this study, clopidogrel response is empirically categorized based on previously established guidelines. It is important to note that LTA and P-VASP have different specificities as LTA also tests for other ADP activation pathways. For that reason, there is also poor agreement among P-VASP and LTA in identifying poor responders to clopidogrel in human beings (24). Second, activation of cAMP and subsequent phosphorylation of VASP in platelets are proportional to the concentration and duration of exposure to $\mathrm{PGE}_{1}$ (9). The dose and duration of $\mathrm{PGE}_{1}$ used in this study may have overwhelmed the competing pathway elicited by $\mathrm{P}_{2} \mathrm{Y}_{12}$ activation in the post-clopidogrel period. Further titration for the optimal concentration and duration of $\mathrm{PGE}_{1}$ treatment is needed to improve the sensitivity of this assay.

Lastly, this study has a few limitations. First, we did not evaluate the within-laboratory precision or repeatability of this assay due to the limited volume of blood samples collected for the study. Further studies examining the precision and repeatability of cytometry quantification of P-VASP in feline platelets are needed. In addition, the high concentration of $\mathrm{PGE}_{1}$, previously utilized to evaluate P-VASP by Western blot analysis, is a limitation. Lastly, only female cats were included in this study. It has been well established that there are gender differences in platelet function in human beings; men have greater platelet adhesion and spreading while women have higher platelet reactivity in the presence of exogenous agonists (25). The evidence of gender differences in response to antiplatelet therapy, however, is inconclusive and likely complicated by fluctuations of androgens and other sex hormones. The fact that male cats are nearly twice as likely to be affected by CATE as female cats suggests that gender differences in platelet function may occur in cats $(3,26)$. Another study also found that female cats had higher

\section{REFERENCES}

1. Payne JR, Brodbelt DC, Luis Fuentes V. Cardiomyopathy prevalence in 780 apparently healthy cats in rehoming centres (the CatScan study). J Vet Cardiol. (2015) 17 (Suppl. 1):S244-57. doi: 10.1016/j.jvc.2015.03.008

2. Atkins CE, Gallo AM, Kurzman ID, Cowen P. Risk factors, clinical signs, and survival in cats with a clinical diagnosis of idiopathic hypertrophic cardiomyopathy: 74 cases (1985-1989). J Am Vet Med Assoc. (1992) 201:613-8.

3. Borgeat K, Wright J, Garrod O, Payne JR, Fuentes VL. Arterial thromboembolism in 250 cats in general practice: 2004-2012. J Vet Intern Med. (2014) 28:102-8. doi: 10.1111/jvim.12249

4. Schoeman JP. Feline distal aortic thromboembolism: a review of 44 cases (1990-1998). J Feline Med Surg. (1999) 1:221-31. doi: 10.1053/jfms.1999.0049

5. Smith SA, Tobias AH, Jacob KA, Fine DM, Grumbles PL. Arterial thromboembolism in cats: acute crisis in 127 cases (1992-2001) and long-term clopidogrel active metabolite than male cats after a single dose of clopidogrel highlighting the gender differences in cytochrome P450 activity (23). Future studies with a population of cats that reflects the signalment of cats at risk of CATE are needed.

\section{CONCLUSION}

Our study shows that analysis of intraplatelet P-VASP by flow cytometry is feasible in feline platelets. This assay can be a useful tool in analyzing the therapeutic efficacy of $\mathrm{P}_{2} \mathrm{Y}_{12}$ antagonists like clopidogrel as well as dysfunction in receptors and platelet signaling.

\section{DATA AVAILABILITY STATEMENT}

The raw data supporting the conclusions of this article will be made available by the authors, without undue reservation, to any qualified researcher.

\section{ETHICS STATEMENT}

The animal study was reviewed and approved by Institutional Animal Care and Use Committee, University of California, Davis.

\section{AUTHOR CONTRIBUTIONS}

RL, KJ, and TR secured funding for this study. RL, NN, KJ, and TR participated in designing the study, sampling of animals, and collection of data. RL and NN performed analysis of the results. $\mathrm{RL}$ drafted the manuscript. All authors were actively involved in the editing of the manuscript.

\section{FUNDING}

This study was funded by the Center for Companion Animal Health (2017-50-R) of the University of California, Davis.

\section{ACKNOWLEDGMENTS}

The authors would like to thank Ms. Maria Montano for her assistance with the study. management with low-dose aspirin in 24 cases. J Vet Intern Med. (2003) 17:73-83. doi: 10.1111/j.1939-1676.2003.tb01326.x

6. Goggs R, Poole AW. Platelet signaling-a primer. J Vet Emerg Crit Care. (2012) 22:5-29. doi: 10.1111/j.1476-4431.2011.00704.x

7. Hogan DF, Fox PR, Jacob K, Keene B, Laste NJ, Rosenthal S, et al. Secondary prevention of cardiogenic arterial thromboembolism in the cat: the doubleblind, randomized, positive-controlled feline arterial thromboembolism; clopidogrel vs. aspirin trial (FAT CAT). J Vet Cardiol. (2015) 17 (Suppl. 1):S306-17. doi: 10.1016/j.jvc.2015.10.004

8. Smolenski A. Novel roles of cAMP/cGMP-dependent signaling in platelets. J Thromb Haemost. (2012) 10:167-76. doi: 10.1111/j.1538-7836.2011. 04576.x

9. Schwarz UR, Geiger J, Walter U, Eigenthaler M. Flow cytometry analysis of intracellular VASP phosphorylation for the assessment of activating and inhibitory signal transduction pathways in human platelets-definition and 
detection of ticlopidine/clopidogrel effects. Thromb Haemost. (1999) 82:114552. doi: 10.1055/s-0037-1614344

10. Smolenski A, Bachmann C, Reinhard K, Honig-Liedl P, Jarchau T, Hoschuetzky $\mathrm{H}$, et al. Analysis and regulation of vasodilator-stimulated phosphoprotein serine 239 phosphorylation in vitro and in intact cells using a phosphospecific monoclonal antibody. J Biol Chem. (1998) 273:20029-35. doi: 10.1074/jbc.273.32.20029

11. Li RH, Stern JA, Ho V, Tablin F, Harris SP. Platelet activation and clopidogrel effects on ADP-induced platelet activation in cats with or without the A31P mutation in MYBPC3. J Vet Intern Med. (2016) 30:1619-29. doi: 10.1111 /jvim. 14568

12. Fedor M, Samos M, Simonova R, Fedorova J, Skornova, Duraj L, et al. Monitoring the efficacy of ADP inhibitor treatment in patients with acute STEMI post-PCI by VASP-P flow cytometry assay. Clin Appl Thromb Hemost. (2015) 21:334-8. doi: 10.1177/1076029614540036

13. Aleil B, Ravanat C, Cazenave JP, Rochoux G, Heitz A, Gachet C. Flow cytometric analysis of intraplatelet VASP phosphorylation for the detection of clopidogrel resistance in patients with ischemic cardiovascular diseases. $J$ Thromb Haemost. (2005) 3:85-92. doi: 10.1111/j.1538-7836.2004.01063.x

14. Hoffmann K, Lutz DA, Strassburger J, Baqi Y, Muller CE, von Kugelgen I. Competitive mode and site of interaction of ticagrelor at the human platelet P2Y12 -receptor. J Thromb Haemost. (2014) 12:1898-905. doi: $10.1111 /$ jth. 12719

15. Savi P, Zachayus JL, Delesque-Touchard N, Labouret C, Herve C, Uzabiaga, et al. The active metabolite of Clopidogrel disrupts $\mathrm{P} 2 \mathrm{Y} 12$ receptor oligomers and partitions them out of lipid rafts. Proc Natl Acad Sci USA. (2006) 103:11069-74. doi: 10.1073/pnas.0510446103

16. Tablin F, Schumacher T, Pombo M, Marion CT, Huang K, Norris JW, et al. Platelet activation in cats with hypertrophic cardiomyopathy. J Vet Intern Med. (2014) 28:411-8. doi: 10.1111/jvim.12325

17. Baschong W, Suetterlin R, Laeng RH. Control of autofluorescence of archival formaldehyde-fixed, paraffin-embedded tissue in confocal laser scanning microscopy (CLSM). J Histochem Cytochem. (2001) 49:1565-72. doi: 10.1177/002215540104901210

18. Kingston JK, Bayly WM, Sellon DC, Meyers KM, Wardrop KJ. Effects of formaldehyde fixation on equine platelets using flow cytometric methods to evaluate markers of platelet activation. Am J Vet Res. (2002) 63:840-4. doi: 10.2460/ajvr.2002.63.840

19. Jandrey KE. Assessment of platelet function. J Vet Emerg Crit Care. (2012) 22:81-98. doi: 10.1111/j.1476-4431.2011.00707.x

20. Bandyopadhyay SK, Azharuddin M, Dasgupta AK, Ganguli B, SenRoy $\mathrm{S}$, Patra $\mathrm{HK}$, et al. Probing ADP induced aggregation kinetics during platelet-nanoparticle interactions: functional dynamics analysis to rationalize safety and benefits. Front Bioeng Biotechnol. (2019) 7:163. doi: 10.3389/fbioe.2019.00163

21. Ohlmann P, Eckly A, Freund M, Cazenave JP, Offermanns S, Gachet C. ADP induces partial platelet aggregation without shape change and potentiates collagen-induced aggregation in the absence of Galphaq. Blood. (2000) 96:2134-9. doi: 10.1182/blood.V96.6.2134

22. Ho KK, Abrams-Ogg AC, Wood RD, O’Sullivan ML, Kirby GM, Blois SL. Assessment of platelet function in healthy cats in response to commonly prescribed antiplatelet drugs using three point-of-care platelet function tests. J Feline Med Surg. (2016) 19:638-47. doi: 10.1177/1098612X16 648182

23. Lee PM, Faus MCL, Court MH. High interindividual variability in plasma clopidogrel active metabolite concentrations in healthy cats is associated with sex and cytochrome P450 2C genetic polymorphism. J Vet Pharmacol Ther. (2019) 42:16-25. doi: 10.1111/jvp.12717

24. Lemesle G, Landel JB, Bauters A, Delhaye C, Bonello L, Sudre A, et al. Poor agreement between light transmission aggregometry, Verify Now $\mathrm{P} 2 \mathrm{Y}(1)(2)$ and vasodilatator-stimulated phosphoprotein for clopidogrel lowresponse assessment: a potential explanation of negative results of recent randomized trials. Platelets. (2014) 25:499-505. doi: 10.3109/09537104.2013. 840363

25. Patti G, De Caterina R, Abbate R, Andreotti F, Biasucci LM, Calabro P, et al. Platelet function and long-term antiplatelet therapy in women: is there a gender-specificity? A 'state-of-the-art' paper. Eur Heart J. (2014) 35:2213-23b. doi: 10.1093/eurheartj/ehu279

26. Payne JR, Borgeat K, Brodbelt DC, Connolly DJ, Luis Fuentes V. Risk factors associated with sudden death vs. congestive heart failure or arterial thromboembolism in cats with hypertrophic cardiomyopathy. J Vet Cardiol. (2015) 17 (Suppl. 1):S318-28. doi: 10.1016/j.jvc.2015.09.008

Conflict of Interest: The authors declare that the research was conducted in the absence of any commercial or financial relationships that could be construed as a potential conflict of interest.

Copyright (c) 2020 Li, Nguyen, Rosati and Jandrey. This is an open-access article distributed under the terms of the Creative Commons Attribution License (CC BY). The use, distribution or reproduction in other forums is permitted, provided the original author(s) and the copyright owner(s) are credited and that the original publication in this journal is cited, in accordance with accepted academic practice. No use, distribution or reproduction is permitted which does not comply with these terms. 